\title{
ANALISIS PENYEBAB BELUM TERLAKSANANYA SISTEM KOMPUTERISASI DI TEMPAT PENDAFTARAN PASIEN RAWAT JALAN (TPPRJ) DI RUMAH SAKIT UMUM DAERAH PETALA BUMI PEKANBARU TAHUN 2015
}

\author{
Nur Maimun, Fitriani Astika \\ STIKES Hang Tuah Pekanbaru \\ Email: nurmaimun83@gmail.com
}

\begin{abstract}
Computers as an electronic gear go through data, able to receive advice and output, the data is the as a high, precision, And the ability keep instructions to solve the problem. This study attempts to find out the cause of unrealized a computerized system in place registration ambulatory in RSUD Petala Bumi pekanbaru years 2015. Research methodology with a qualitative approach. technics data collection by means of observation, interviews and documentation. Data analysis qualitative analysis. The results of the study because the hospital new this year become the house district general hospital while first still in under UPT provincial health office riau. Human resources in components of the system computerized not enough. Facilities and infrastructure for a computerized system there has been no. There is no sop to a computerized system, and funding of the have been over budgeted but still in the process. In suggest: the sum of human resources in addition, make facilities and infrastructure, sop at the record medical and needs to be improved again efforts advocacy that ususlan budget / cost to a computerized system in TPPRJ can be processed by related parties.
\end{abstract}

Keywords: A computerized system, registration patients, ambulatory

\section{PENDAHULUAN}

Komputer sebagai suatu perlengkapan elektronik yang mengolah data, mampu menerima masukan dan keluaran, data mempunyai sifat seperti kecepatan yang tinggi, ketelitian, dan kemampuan menyimpan instruksi-instruksi untuk memecahkan masalah. Komputer tidak dapat mulai berpikir, membetulkan kesalahan sendiri, atau melakukan pengolahan yang sifatnya kreatif. Akan tetapi, penemuan kesalahan yang sifatnya rutin dapat diprogramkan ke dalam komputer sehingga komputer tersebut dapat memberikan peringatan kepada operatornya mengenai kesalahankesalahan yang dibuat.

Pelayanan rekam medis yang baik dan bermutu adalah pelayanan yang cepat. Pelayanan rekam medis rawat jalan dimulai dari tempat pendaftaran sampai memperoleh dokumen rekam medis yang akan dijadikan sebagai salah satu untuk mendapatkan pelayanan kesehatan. Berdasarkan standar pelayanan minimal pendaftaran pasien rawat jalan adalah 10 menit (DepKes 2007).

Berdasarkan Survei awal Sistem Informasi Rumah Sakit (SIRS) di Unit rekam medis sudah dilaksanakan. hanya saja keseluruhannya belum terlaksana secara elektronik / komputerisasi. SIRS yang berbasis komputerisasi baru terlaksana di bagian pelaporan dan Kartu Identitas Pasien sedangkan di unit tempat pendaftaran pasien rawat jalan (TPPRJ) belum terlaksana karena kurangnya sarana dan prasarana seperti jumlah komputer, sistem jaringan yang belum terkoneksi keseluruh unit terkait.

Tabel 1. Jumlah Kunjungan Pasien Rawat Jalan di RSUD Petala Bumi Pekanbaru Tahun 2012-2014

\begin{tabular}{lllll}
\hline No. & Tahun & $\begin{array}{l}\text { Jumlah } \\
\text { Kunjungan } \\
\text { per Tahun }\end{array}$ & $\begin{array}{l}\text { Rata-Rata } \\
\text { Kunjungan } \\
\text { per Bulan }\end{array}$ & $\begin{array}{l}\text { Rata-Rata } \\
\text { Kunjungan } \\
\text { per Hari }\end{array}$ \\
\hline 1. & 2012 & 35709 & 2976 & 100 \\
2. & 2013 & 45332 & 3778 & 128 \\
3. & 2014 & 35976 & 2998 & 101
\end{tabular}

Sumber: Rumah Sakit Umum Daerah Petala Bumi

RSUD Petala Bumi Pekanbaru belum melaksanakan sistem komputerisasi di unit pelayanan pendaftaran rawat jalan dalam penerimaan pasien baru atau pasien lama, petugas rekam medis hanya melayani pasien secara manual, sehingga pada saat pasien 
berkunjung dan pasien tidak membawa kartu berobat mengakibatkan petugas sulit untuk mencari berkas rekam medis dan kartu berobat yang mengakibatkan pasien harus mengantri dan menunggu terlalu lama. Hal ini akan menghambat efektifitas dan efisiensi petugas dalam memberikan pelayanan kepada pasien. Maka didapatkan informasi sementara bahwa rumah sakit tersebut akan merencanakan pelaksanaan sistem komputerisasi di unit tempat pendaftaran pasien rawat jalan (TPPRJ).

Adapun tujuan dari penelitian ini adalah untuk mengetahui penyebab belum terlaksananya sistem komputerisasi di Tempat
Pendaftaran Pasien Rawat Jalan (TPPRJ) di Rumah Sakit Umum Daerah Petala Bumi.

\section{METODOLOGI PENELITIAN}

Jenis penelitian dengan deskriptif pendekatan kualitatif. Subjek dalam penelitian ini adalah Kepala Rekam Medis dan Petugas Rekam Medis yang bertanggung jawab dalam pelaksanaan Pendaftaran Pasien rawat jalan rekam medis. Teknik analisis data analisis kualitatif yang diperoleh dari metode wawancara, observasi dan hasil penelusuran dokumen melalui cara induktif. Data dianalisis secara deskriptif dengan menggunakan teknik Content Analysis.

\section{HASIL DAN PEMBAHASAN \\ Observasi}

Tabel 2. Hasil Observasi

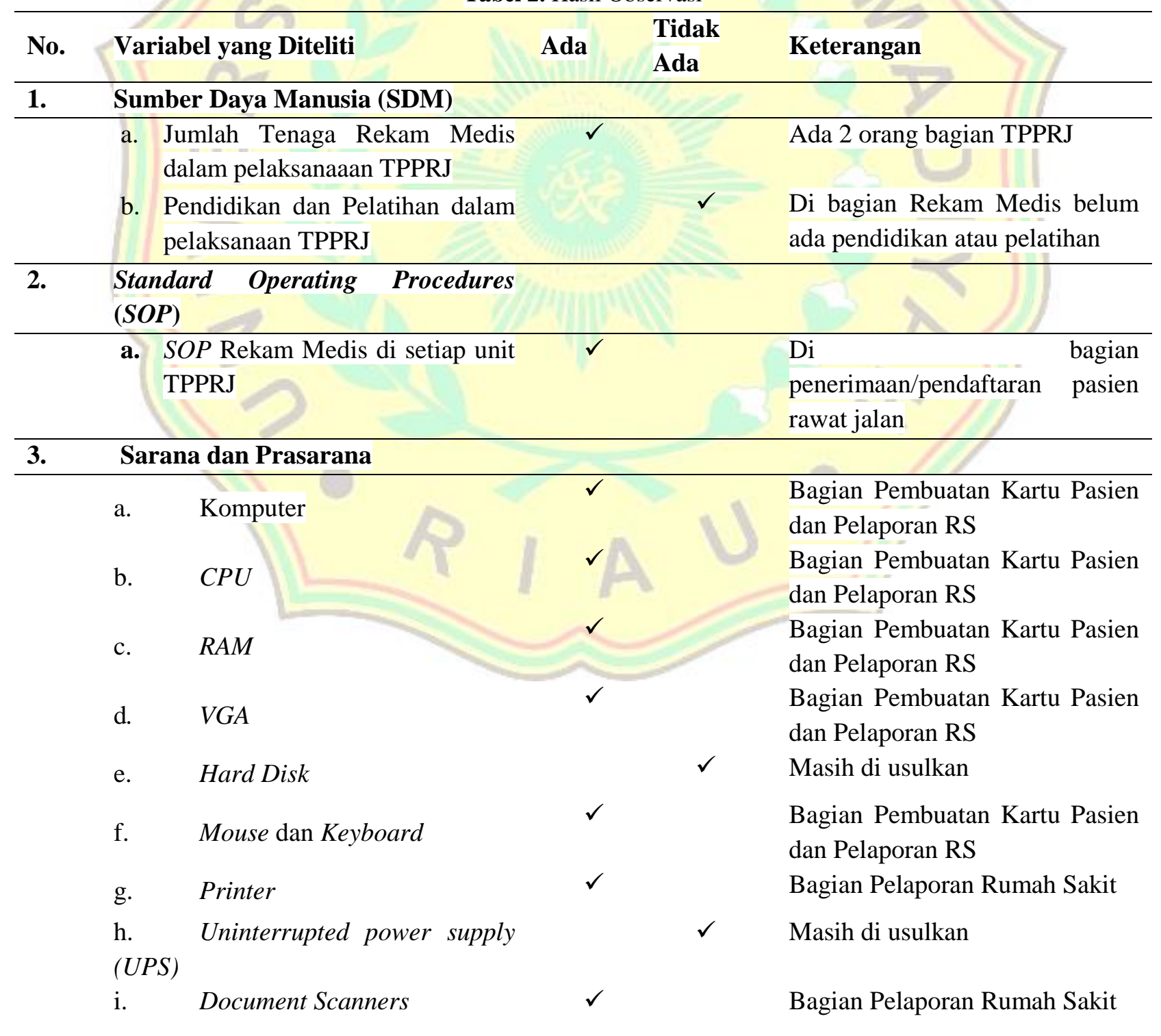




\begin{tabular}{cccll}
\hline No. & Variabel yang Diteliti & Ada & $\begin{array}{l}\text { Tidak } \\
\text { Ada }\end{array}$ & Keterangan \\
\hline j. & Wireless Fidelity $($ WiFi $)$ & $\checkmark$ & & Di ruangan Rekam Medis \\
k. & Local Area Networks $(L A N)$ & $\checkmark$ & & Masih Uji Coba \\
\hline
\end{tabular}

4. Program Aplikasi (Software dan

Hardware)
a. Sistem Operasi
b. Program Aplikasi
Masih di usulkan
Masih di usulkan

Sumber: Data Primer RSUD Petala Bumi Pekanbaru Tahun 2015

Hasil Wawancara

1. Penyebab dari Komponen Input di TPPRJ meliputi (SDM, Sarana dan Prasarana, Pembiayaan)

Berdasarkan hasil wawancara dengan informan, diketahui Penyebab dari komponen input di TPPRJ. Seperti pernyataan berikut:

"Faktor sumber daya manusia memepengaruhi terhadap pelayanan di TPPRJ RSUD Petala Bumi Pekanbaru karena Sumber daya manusia berperan penting dalam pelaksanaan pelayanan terhadap pasien di TPPRJ RSUD Petala Bumi Pekanbaru dan sampai sekarang penyebab belum dilaksanakannya sistem komputerisasi TPPRJ RSUD Petala Bumi dikarenakan Rumah sakit ini baru menjadi rumah sakit umum pada bulan Februari 2015 sedangkan dulu masih di bawahi UPT Dinas Kesehatan Propinsi Riau". (Informan 1).

"Sumber daya manusia memepengaruhi terhadap pelayanan di TPPRJ RSUD Petala Bumi Pekanbaru dan sampai sekarang penyebab belum dilaksanakannya sistem komputerisasi TPPRJ RSUD Petala Bumi dikarenakan belum ada anggaran/Dana" (Informan 2).

"Faktor sumber daya manusia memepengaruhi terhadap pelayanan di TPPRJ RSUD Petala Bumi Pekanbaru karena Sumber daya manusia berperan penting dan sampai sekarang penyebab belum dilaksanakannya sistem komputerisasi TPPRJ RSUD Petala Bumi dikarenakan tempat /ruangan MR yang tidak mendukung dan belum tersedianya komputer di bagian pendaftaran rawat jalan" (Informan 3, 4).
2. Persiapan Perencanaan Sistem Komputerisasi di TPPRJ RSUD Petala Bumi Pekanbaru Tahun 2015

a. Persiapan Perencanaan Sumber Daya Manusia (SDM) Rekam Medis

Berdasarkan hasil wawancara terhadap beberapa informan, diperoleh informasi untuk SDM rekam medisnya belum tercukupi. Seperti pernyataan berikut:

"Sumber daya manusia di ruang rekam medis khususnya dalam pengelolaan rekam medis secara komputerisasi belum cukup, upaya yang dilakukan untuk meningkatkan kualitas SDM rekam medis di RSUD Petala Bumi akan memberikan pelatihan ke petugas rekam medis khususnya pada pendaftaran rawat jalan, latar belakang pendidikan memberikan pengaruh terhadap SDM di rekam medis, pelatihan sudah ada, yang mengikutinya 2 orang dari bagian rekam medis tentang pelatihan SIMRS Studi banding pada tahun 2013 di jakarta dan adanya rencana untuk penambahan SDM untuk rekam medis" (Informan 1,2).

"Sumber daya manusia di ruang rekam medis khususnya dalam pengelolaan rekam medis secara komputerisasi belum cukup, upaya yang dilakukan untuk meningkatkan kualitas SDM rekam medis di RSUD Petala Bumi akan memberikan pelatihan-pelatihan ke petugas rekam medis khususnya pada pendaftaran rawat jalan, latar belakang pendidikan memberikan pengaruh terhadap SDM di rekam medis karena jika pendidikan sesuai dengan bidangnya maka perencanaan akan berjalan sesuai dengan yang di inginkan, selama bekerja di rekam medis belum pernah dilakukan pelatihan-pelatihan 
mengenai pengelolaan rekam medis secara komputerisasi" (Informan 3).

"Sumber daya manusia di ruang rekam medis khususnya dalam pengelolaan rekam medis secara komputerisasi belum cukup, upaya yang dilakukan untuk meningkatkan kualitas SDM rekam medis di RSUD Petala Bumi akan memberikan pelatihan ke petugas rekam medis khususnya pada pendaftaran rawat jalan, latar belakang pendidikan memberikan pengaruh terhadap SDM di rekam medis,karena kerja di ruangan apapun bisa dipelajari dasarnya dengan berinteraksi dan banyak bertanya pada orang/petugas yang lebih tau, selama bekerja di rekam medis belum pernah dilakukan pelatihanpelatihan karena masih baru menempati / bertugas di MR" (Informan 4).

b. Persiapan Perencanaan Sarana dan prasarana

Berdasarkan hasil wawancara terhadap beberapa informan, diperoleh informasi yaitu untuk Sarana dan Prasarana Seperti pernyataan berikut:

"Sarana dan prasarana yang dibutuhkan untuk pelaksanaan sistem komputerisasi yaitu, komputer, wifi dan lain-lain sedangkan untuk program aplikasi (Software dan Hardware) di bagian pendaftaran RSPB Belum ada, untuk sarana dan prasarana akan dibuat atau direncanakan" (Informan 1).

"Sarana dan prasarana yang dibutuhkan untuk pelaksanaan sistem komputerisasi yaitu, komputer, wifi dan lain-lain sedangkan untuk program aplikasi (Software dan Hardware) di bagian pendaftaran RSPB Belum ada, rencana untuk sarana dan prasarana saya tidak tahu." (Informan 2).

"Sarana dan prasarana yang dibutuhkan untuk pelaksanaan sistem komputerisasi yaitu, komputer, wifi dan lain-lain sedangkan untuk program aplikasi (Software dan Hardware) di bagian pendaftaran RSPB Belum ada." (Informan 3, 4).
c. Persiapan Perencanaan Standard Operating Procedures (SOP) tentang Pelaksanaan Sistem Komputerisasi TPPRJ

Berdasarkan hasil wawancara terhadap beberapa informasi bahwa Standard Operating Procedures (SOP) untuk masing-masing pengolahan rekam medis sudah ada, Cuma untuk SOP pelaksanaan Sistem Komputerisasi di TPPRJ belum ada. Seperti pernyataan informan berikut:

"SOP untuk rekam medis sudah ada mulai dari SPO tentang penerimaan pasien sampai penyimpanan file rekam medis tetapi untuk SOP pelaksanaan Sistem Komputerisasi di TPPRJ belum ada, saya tidak tahu adanya perencanaan dalam pembuatan SOP Rekam Medis di TPPRJ" (Informan 1).

"Mengenai Standard Operating Procedures (SOP) belum dibuat SOP nya, karena belum ada sistem komputerisasinya, belum tau kapan akan dirancanakan pembuatan SOP untuk Rekam Medis di TPPRJ. "(Informan 2, 3,4).

3. Persiapan Perencanaan Pembiayaan/Dana Sistem Komputerisasi TPPRJ di RSUD Petala Bumi Tahun 2015

Berdasarkan hasil wawancara terhadap beberapa informan diperoleh informasi bahwa Pembiayaan/Dana Sistem Komputerisasi TPPRJ di RSUD Petala Bumi Tahun 2015, maka didapatkan informasi sebagai berikut:

"Pembiayaan/Dana Sistem Komputerisasi TPPRJ di RSUD Petala Bumi Tahun 2015 Sudah tersedia, masih di usulkan insya allah tahun ini akan dilaksanakan"(Informan 1).

"saya tidak mengetahui biaya untuk pengelolaan sistem komputerisasi di TPPRJ tersedia atau tidak dan untuk seberapa besar pengaruh biaya untuk TPPRJ Rekam Medis secara komputerisasi sangat berpengaruh, karena apabila biaya sudah ada, sistem komputerisasi di bagian pendaftaran akan terlaksana dengan baik. Untuk rencana dilaksakannya sistem komputerisasi TPPRJ ada, secepatnya atau semoga ajha tahun depan sudah terlaksana.amin"'(Informan 2, 3, 4).

\section{Pembahasan}
1.Penyebab dari Komponen Input di TPPRJ Meliputi (SDM, Sarana dan Prasarana, Pembiayaan)


Berdasarkan hasil penelitian dari beberapa informan sampai sekarang penyebab belum dilaksanakannya sistem komputerisasi TPPRJ dikarenakan rumah sakit ini baru menjadi rumah sakit umum pada bulan Februari 2015 sedangkan dulu masih di bawahi UPT Dinas Kesehatan Propinsi Riau dan juga sarana dan prasarana tempat/ruangan MR yang tidak mendukung, belum tersedianya komputer di bagian pendaftaran rawat jalan dan pembiayaan yang belum di cairkan untuk sistem komputerisasi.

Berdasarkan Pendapat Jugiyanto (2005) yang mengutip hasil penelitian Nurnanik (2013) dapat disimpulkan bahwa manfaat sistem komputerisasi bagi pelayanan pasien di rumah sakit sangat penting. Selain untuk memberikan pelayanan yang cepat, sistem komputerisasi juga dapat berfungsi sebagai penyimpanan informasi pasien dalam jangka panjang, dan juga berfungsi sebagai pembuatan laporan-laporan lainnya yang bersangkutan dalam pelayanan kesehatan.

Pelaksanaan rekam medis yang baik membutuhkan penerapan sistem informasi yang berbasis komputer, karena aplikasi ini memberikan kemudahan untuk menyimpan, memperbaharui, mengakses dan mencari catatan-catatan medis pasien lengkap dan cepat.

\section{Persiapan Perencanaan Sistem Komputerisasi di TPPRJ RSUD Petala Bumi Pekanbaru Tahun 2015}

a. Persiapan Perencanaan Sumber Daya Manusia (SDM)

Menurut hasil penelitian diperoleh informasi bahwa Sumber Daya Manusia untuk pengelolaan rekam medis secara komputerisasi belum cukup, upaya untuk meningkatkan kualitas SDM mengikuti pelatihan - pelatihan dan pendidikan juga berpengaruh, karena jika pendidikan sesuai dengan bidangnya maka perencanaan akan berjalan sesuai dengan yang di inginkan.

Hasil penelitian ini sejalan dengan penelitian yang dilakukan oleh Putriani Khairiah (2014) Bahwa Sumber Daya Manusia sangat berpengaruh pada penerapan IT pada pengelolan rekam medis.

Sumber Daya Manusia adalah tatanan yang menghimpun berbagai upaya perencanaan, pendidikan, dan pelatihan serta pendayagunaan tenaga kesehatan secara terpadu dan saling mendukung, guna menjamin tercapainya derajat kesehatan masyarakat yang setinggi-tingginya (Adisasmito, 2010).

Suatu Rumah Sakit selalu menghadapi masalah mengenai kekurangan tenaga. Adanya upaya yang dilakukan meningkatkan kualitas pelayanan serta ilmu pengetahuan dan tekhnologi yang canggih, maka dalam suatu rumah sakit harus mencukupi sumber daya manusianya.

b. Persiapan Perencanaan Sarana dan Prasarana

Berdasarkan hasil penelitian didapat bahwa ketersediaan sarana dan prasarana tentang sistem komputerisasi di TPPRJ di RSUD Petala Bumi Pekanbaru untuk saat ini belum memadai, hanya di beberapa tempat saja yang pakai sistem komputerisasi seperti pembuatan Kartu Pasien dan Pelaporan Rumah sakit.

Hasil penelitian ini sejalan dengan penelitian yang dilakukan oleh Putriani Khairiah (2014) Bahwa Sarana dan prasarana sangat penting dalam pelaksanaan sistem Informasi IT.

Menurut Kamus Besar Bahasa Indonesia (KBBI) sarana adalah suatu macam alat untuk mempermudah pekerjaan, maksud atau tujuan dan upaya yang akan dilakukan.

Pimpinan Rumah sakit bertanggungjawab menyediakan sarana dan fasilitas untuk kegiatan unit/bagian rekam medis yang meliputi ruangan kegiatan, rak file, komputer, peralatan penunjang, kegiatan dan petugas rekam medis. Dengan demikian petugas rekam medis dapat bekerja dengan efektif dan efesien (Depkes RI, 2006).

\section{c. Persiapan Perencanaan Standard Operating Procedures (SOP)}

Berdasarkan hasil penelitian didapat bahwa SOP tentang sistem komputerisasi di TPPRJ RSUD Petala Bumi Pekanbaru belum ada.

SOP pada dasarnya adalah pedoman yang berisi prosedur-prosedur oprasional standar yang ada di dalam suatu organisasi yang digunakan untuk memastikan bahwa setiap keputusan, langkah, atau tindakan, dan pengunaan fasilitas pemrosesan yang dilaksanakan oleh orang-orang 
didalam suatu organisasi, telah berjalan secara efektif, konsisten, standar, dan sistematis (Tambunan, 2013)

Perencanaan Standard Operating Procedures (SOP) dalam setiap penerapan sistem komputerisasi TPPRJ Rekam medis perlu dibuat dalam suatu organisasi, karena SOP merupakan suatu aturan baku yang sangat penting.

d. Persiapan Perencanaan Pembiayaan

Berdasarkan hasil penelitian didapat bahwa pembiayaan tentang sistem komputerisasi di TPPRJ RSUD Petala Bumi Pekanbaru belum ada, tapi akan direncanakan tahun ini.

Hasil penelitian ini sejalan dengan penelitian yang dilakukan oleh Devi Fitri (2012) bahwa pembiayaan di anggarkan untuk sistem informasi agar terlaksana pengelolaan rekam medis yang baik.

Biaya terbagi menjadi dua, yaitu:

$$
\text { a) Biaya Eksplisit }
$$

Adalah biaya yang terlihat secara fisik misalnya berupa uang.

b) Biaya Implisit

Adalah biaya yang tidak terlihat secara langsung. Misalnya biaya kesempatan dan penyusutan barang.

\section{KESIMPULAN DAN SARAN}

\section{Kesimpulan}

1. Sumber daya manusia di ruang rekam medis secara komputerisasi belum cukup, seharusnya menambah petugas rekam medis khususnya tempat pendaftaran Pasien rawat jalan RSUD Petala Bumi Pekanbaru.

2. Sarana dan prasarana yang dibutuhkan untuk pelaksanaan sistem komputerisasi yaitu, komputer, wifi dan lain-lain sedangkan untuk program aplikasi (Software dan Hardware) di bagian pendaftaran belum ada.

3. SOP pelaksanaan Sistem Komputerisasi di TPPRJ belum ada, karena belum dibuat.

4. Pembiayaan untuk pengelolaan sistem komputerisasi di TPPRJ sudah di usulkan atau di anggarkan, tetapi masih dalam proses perencanaan sistem informasi aplikasi software dan hardware di TPPRJ RSUD Petala Bumi.

\section{Saran}

1. Jumlah Sumber Daya Manusia (SDM) masih kurang dan hendaknya di tambah lagi untuk pelaksanaan sistem komputerisasi di TPPRJ dengan melakukan pelatihanpelatihan tentang sistem Informasi serta dipercepat proses pembiayaan agar terlaksananya sistem komputerisasi di TPPRJ RSUD Petala Bumi Pekanbaru.

2. Perlu perencanaan pembuatan program agar membuat aplikasi (Software dan Hardware) di bagian pendaftaran RSUD Petala Bumi.

\section{DAFTAR PUSTAKA}

Adisasmito, W. (2010) Sistem Kesehatan, Jakarta: Raja Gafindo

Aditama, T.Y. (2010). Manajemen Administrasi Rumah Sakit. Jakarta: Universitas Indonesia.

Azwar, A. (2010). Pengantar Administrasi Kesehatan Edisi Ketiga. Jakarta: Binarupa Aksara.

DepKes RI. (2006). Pedoman Penyelenggaraan dan Prosedur Rekam Medis Rumah Sakit di Indonesia. Jakarta.

DepKes RI (2007). Buku Petunjuk Pengisian Pengolahan dan Penyajian Data Rumah Sakit. Jakarta.

Fitri Devi (2012). Analisis Sistem Informasi Manajemen Pengelolaan Rekam Medis di Rumah Sakit Lancang Kuning Tahun 2012. Skripsi. Program Studi Ilmu Kesehatan Masyarakat. STIKes Hang Tuah: Pekanbaru

Khairiah Putriani (2014). Analisis Penerapan Informasi Tekhnologi (IT) Pengelolaan Rekam Medis RSI Ibnu Sina Pekanbaru Tahun 2014. Skripsi. Program Studi Ilmu Kesehatan Masyarakat. STIKes Hang Tuah: Pekanbaru

Moleong, L.J. (2004). Metodologi Penelitian Kualitatif. Bandung: PT Remaja Rosdakarya.

Notoatmodjo, S. (2005). Metodologi Penelitian Kesehatan. Jakarta: Rineka Cipta. ,(2009). Pengembangan Sumber Daya Manusia. Jakarta: PT Rineka Citra. 
Tambunan (2013). Standard Operating Procedures (SOP). Jakarta Selatan: Suka Buka

Wawan, A dan M. Dewi. (2010). Teori \&
Pengukuran Pengetahuan, Perilaku, dan Perilaku Manusia. Yogyakarta: Nuha Medika.

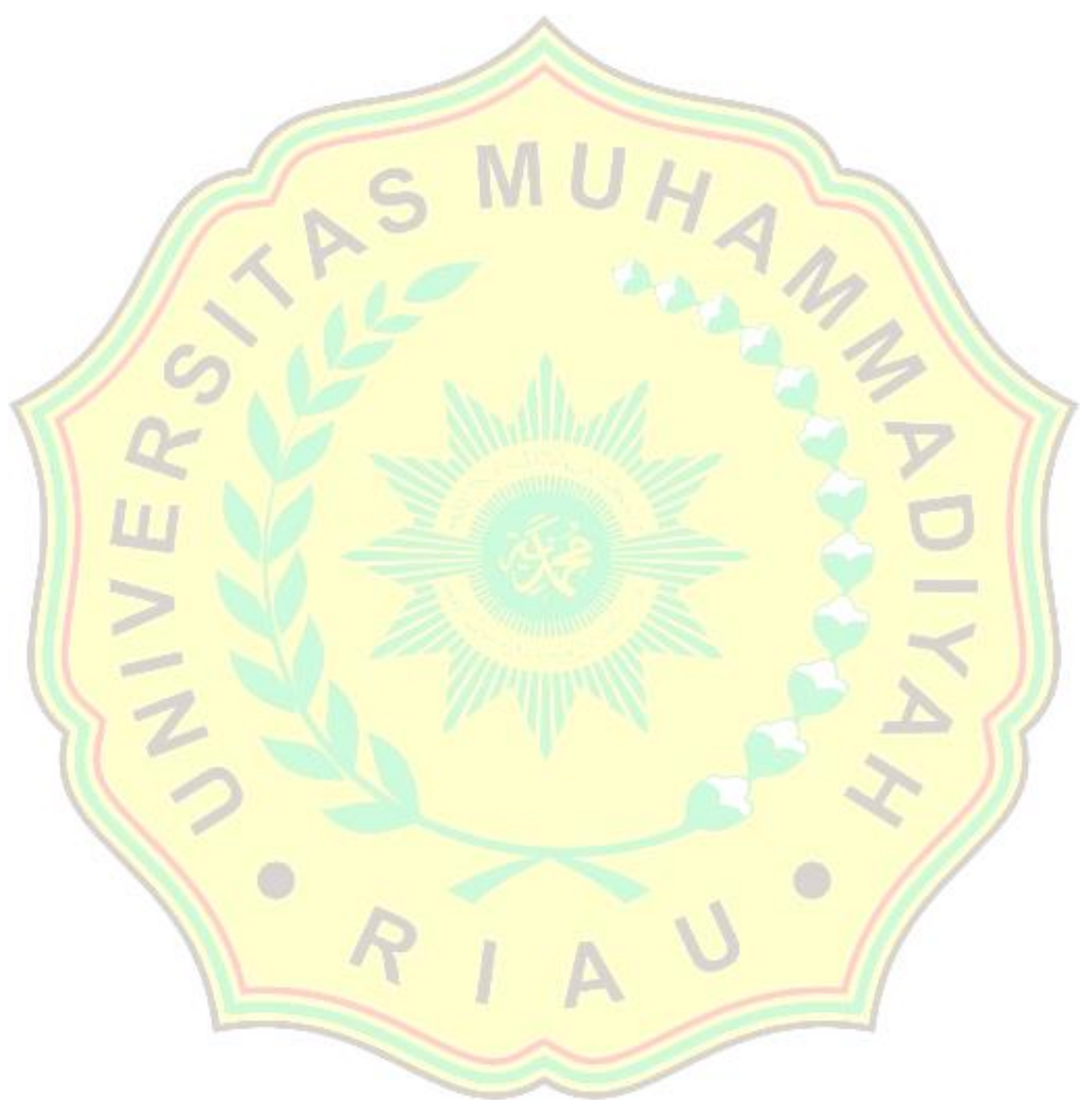

